\title{
Anterior-segment morphology and corneal biomechanical characteristics in pigmentary glaucoma
}

This article was published in the following Dove Press journal:

Clinical Ophthalmology

24 December 2013

Number of times this article has been viewed

\section{Annemarie Klingenstein Marcus Kernt Florian Seidensticker Anselm Kampik Christoph Hirneiss}

Department of Ophthalmology, University of Munich Hospital, Ludwig-Maximilians University, Munich, Germany
Correspondence: A Klingenstein Ludwig-Maximilians University, Department of Ophthalmology, Klinikum der Universität München, Campus Innenstadt, Mathildenstraße 8, D-80336 Munich, Germany

Tel +49895160 38II

Fax +498951605160

Email annemarie.klingenstein@med.unimuenchen.de
Purpose: The aim of the study reported here was to evaluate characteristics of the anteriorsegment via anterior-segment optical coherence tomography (AS-OCT) and corneal biomechanical properties using an ocular response analyzer and their changes by peripheral laser iridotomy (PI) in patients with pigmentary glaucoma (PG).

Materials and methods: Seventeen eyes with PG were included consecutively. AS-OCT and ocular response analyzer measurements were taken before and 3 months after PI. Baseline morphology and change in morphology were analyzed by correlation and multiple linear regression analysis. The main parameters assessed were anterior-chamber (AC) angles and volume as well as corneal hysteresis $(\mathrm{CH})$ and corneal resistance factor.

Results: AC angles were found to have decreased significantly in each quadrant after PI $(P<0.001)$, with the highest effect seen in the temporal quadrant, which decreased from $57.0^{\circ} \pm 9.6^{\circ}$ to $44.1^{\circ} \pm 5.2^{\circ}$ ( \pm standard deviation). Mean $\mathrm{AC}$ volume decreased significantly from $213.1 \pm 36.4$ to $187.0 \pm 23.4 \mathrm{~mm}^{3}(P<0.001)$. $\mathrm{CH}$ and corneal resistance factor did not change after PI. CH was found to correlate with the preoperative superior and inferior angle width (Spearman's rho 0.553 and 0.615 , respectively, $P<0.05$ ). Biomechanical parameters showed no predictive value on the change of AC angles or volume.

Conclusion: PI in eyes with PG results in a highly significant reduction in the AC angles and volume as visualized by AS-OCT, with the largest effect seen in the temporal quadrant. $\mathrm{CH}$ is strongly positively correlated with the superior and inferior preoperative AC angles, emphasizing the importance of the biomechanical properties of the cornea for glaucoma pathogenesis in PG, but corneal biomechanical properties cannot predict PI-related AC changes.

Keywords: anterior-segment optical coherence tomography, ocular response analyzer, corneal hysteresis

\section{Introduction}

Pigmentary glaucoma (PG) and pigment dispersion syndrome (PDS) are subtypes of secondary open-angle glaucoma (OAG). Both represent a spectrum of the same disease characterized by excessive pigment liberation throughout the anterior segment of the eye and account for $1.0 \%-1.5 \%$ of glaucoma cases in the Western world. ${ }^{1}$ Although rare, PG and PDS tend to occur at a younger age than primary OAG. Typically, young male myopic patients are affected. Average age at onset is between the third and fifth decades and advanced glaucomatous optic-nerve damage at time of presentation is not uncommon. The underlying mechanism responsible for PG and PDS is friction of the posterior iris surface against the anterior lens zonular bundles during physiological pupil movement caused by a concave iris contour (posterior bowing). This leads 
to a disruption of the iris pigment epithelial cell membrane and release of pigment granules. Clinical features include the presence of Krukenberg's spindle, iris transillumination defects, and trabecular meshwork pigmentation., ${ }^{1,2}$ Posterior bowing of the mid peripheral iris is of particular importance in the etiology of PDS, as it results in a close irido-zonular contact that can be confirmed by ultrasound biomicroscopy (UBM) and anterior-segment optical coherence tomography (AS-OCT). In PG, for example, it has been demonstrated that the insertion of the iris into the ciliary body is more posterior. ${ }^{3}$ This has been suggested to increase the irido-zonular contact and induce a more significant clinical picture. ${ }^{3}$ Histologic studies revealed that areas of disrupted iris pigment epithelium had a radial distribution corresponding to the peripheral iris transillumination defects, ${ }^{4,5}$ supporting the concepts originally proposed by Campbell. ${ }^{4}$

"AS-OCT" is a noninvasive technique allowing the visualization and measurement of the anterior ocular structures. It provides an image of the entire anterior-segment in a single frame. Anterior-segment parameters may be quantitatively assessed using a noncontact method with the patient in a sitting position. ${ }^{6}$ Therefore, it has proven a valuable tool for visualizing and monitoring anterior-chamber $(\mathrm{AC})$ structures in several diseases including glaucoma. Peripheral laser iridotomy (PI) relieves the reverse-pupillary block by preventing posterior concavity of the iris, which probably induces pigment dispersion. ${ }^{4,7}$ Specific changes in the anterior-segment morphology after PI can be quantified by AS-OCT. ${ }^{8}$

The ocular response analyzer (ORA) has been developed to measure the in vivo biomechanical properties of the cornea. It indirectly assesses corneal hysteresis $(\mathrm{CH})$, which may be a measure of ocular viscous properties reflecting the tissue capacity to absorb and dissipate energy, and corneal resistance factor (CRF), which may be a measure of overall ocular rigidity. A number of studies found that low $\mathrm{CH}$ is associated with certain forms of glaucoma and that progressive visual-field loss in glaucoma may be associated with low CH. ${ }^{9}$ As cornea and sclera are continuous collagenous sheaths of the eye, they are built from similar extracellular matrix constituents, ${ }^{10}$ suggesting that biomechanical properties of the lamina cribrosa also correlate with the corneal characteristics evaluated. ${ }^{11}$ Corneal properties may be related to the resistance of the optic-nerve head $^{12}$ and are therefore of interest in glaucoma patients.

To date, as far as we are aware, the biomechanical properties of PG eyes have not been studied in detail. The objective of this study was therefore to evaluate biomechanical properties of PG eyes and the predictive value of these properties with regard to changes after PI.

\section{Patients and methods}

This study was a prospective investigation conducted in a German university-affiliated glaucoma center. Patients were recruited consecutively. Inclusion criteria were PG due to PDS with documented backward bowing of the iris and glaucomatous alteration of the optic-nerve head with an elevated cupdisc ratio (median $=0.8$ ). In one of the nine patients included, only one eye fulfilled the inclusion criteria, as PG was unilateral. The study was approved by the Institutional Review Board of the Department of Ophthalmology of Ludwig-Maximilians University, Munich, Germany, and was in accordance with the Declaration of Helsinki. Informed consent was obtained from all patients prior to inclusion. All study participants were Caucasian phakic patients and underwent a full ophthalmic examination, including objective and subjective refraction, slit-lamp biomicroscopy, intraocular pressure (IOP) measurement with Goldmann applanation tonometry, gonioscopy, dilated fundus examination by indirect ophthalmoscopy, and central corneal thickness measurement prior to and after PI (for patient details see Table 1). A 30-2 Humphrey ${ }^{\circledR}$ Field Analyzer (HFA $^{\text {TM }}$ II-i; Carl Zeiss Meditec, Munich, Germany) with PeriData software for Windows, Version 2.3 (PeriData Software $\mathrm{GmbH}$, Huerth, Germany) was employed for visual-field testing. Perimetric status was assessed with a mean deviation of $-7.0 \pm 8.0$ and a pattern standard deviation of $5.3 \pm 4.3$. All eyes showed strong pigmentation of the trabecular meshwork in gonioscopy. Other than PG, no further ophthalmologic pathologies were known.

Laser PI was performed between 11 and 1 o'clock using a neodymium-doped yttrium aluminum garnet laser (single dose of 3.2-11.2 mJ, 2-17 shots). Patency of PI was ensured by pigment flowing into the AC directly after laser application. At follow-up, the iridotomy was confirmed to

Table I Demographic characteristics ( $\mathrm{N}=17)$

\begin{tabular}{lll}
\hline Characteristic & $\begin{array}{l}\text { Baseline } \\
\text { ( } \begin{array}{l}\text { standard } \\
\text { deviation) }\end{array}\end{array}$ & After PI \\
\hline Median age (range 3I-5I) (y) & 42 & $(\mathrm{k})$ \\
Sex (male:female) & $17: 0$ & $(\mathrm{k})$ \\
Pachymetry $(\mu \mathrm{m})$ & $544 \pm 33$ & $(\mathrm{k})$ \\
Krukenberg's spindle & $47 \%$ & $(\mathrm{k})$ \\
Spherical equivalent (D) & $-3.2 \pm \mathrm{I} .4$ & $(\mathrm{k})$ \\
Cup-disc ratio & $0.8 \pm 0.2$ & $(\mathrm{k})$ \\
Median BCVA (Snellen) & $20 / 25$ & $20 / 25$ \\
GAT & $15.0 \pm 4.2$ & $\mathrm{I} 3.2 \pm 2.3$ \\
Treatments $(\mathrm{n})$ & $0.7 \pm 0.9$ & $0.9 \pm 0.8$ \\
\hline
\end{tabular}

Abbreviations: BCVA, best-corrected visual acuity (Snellen); D, diopter; GAT, Goldmann applanation tonometry; (k), unchanged; N, total number; n, category number; PI, peripheral laser iridotomy; $y$, years. 
be patent and adequate in size via positive transillumination and change of anterior-segment configuration on AS-OCT. Baseline and follow-up visits were all scheduled in the morning to avoid bias due to diurnal variation upon IOP.

\section{AS-OCT}

In our study, AS-OCT (SL-OCT ${ }^{\mathrm{TM}}$; Heidelberg Engineering $\mathrm{GmbH}$, Heidelberg, Germany) was performed under standard illumination conditions (approximately $10 \mathrm{lux}$ ) in a nonaccommodative state before PI and 3 months afterward. Three images of each quadrant (first superiorly, then inferiorly, temporally, and nasally) were taken and analyzed using Heidelberg Eye Explorer software Version 5.32 (Heidelberg Engineering $\mathrm{GmbH})$. Whenever necessary, the upper lid was lifted up for complete imaging of the chamber angle. Optical coherence tomography scans were acquired with the protocol anterior segment single $0^{\circ}$ to $180^{\circ}(8 \times 16 \mathrm{~mm}$ [depth $\times$ width], with $256 \mathrm{~A}$-scans per line) and the scan line was manually adjusted to bisect the pupil. The scleral spur was marked manually and the angle opening was determined by a single examiner (AK) blinded to the status of the eye (Figure 1). Parameters assessed by AS-OCT included angle width in all four quadrants $(3,6$, 9, and 12 o'clock meridians) and AC volume.

\section{Corneal biomechanics}

Corneal biomechanical properties were measured before and 3 months after PI by the ORA (Reichert Ophthalmic Instruments, Depew, NY, USA). The ORA determines corneal biomechanical properties using an applied forcedisplacement relationship. The details have been described previously. ${ }^{9,13-18}$ Briefly, the difference between the inward and outward motion applanation pressures is the $\mathrm{CH}$ and is an indicator of viscous damping in the cornea. The "CRF"
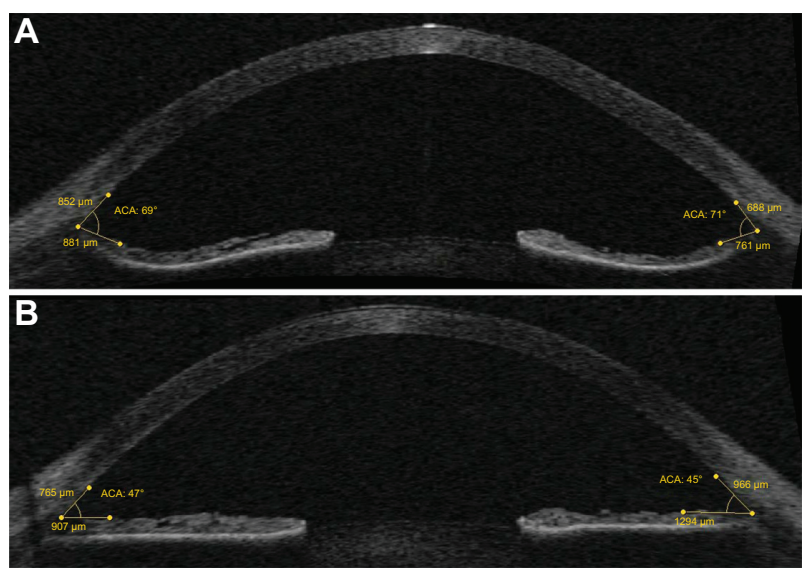

Figure I Changes of the anterior chamber angles (transversal imaging) before (A) and after (B) peripheral laser iridotomy in the same eye. is a measure of the cumulative effects of both the viscous and elastic overall resistance of the cornea. Biomechanical and pressure values recorded included $\mathrm{CH}, \mathrm{CRF}$, corneal compensated intraocular pressure $\left(\mathrm{IOP}_{\mathrm{CC}}\right)$, and Goldmannequivalent intraocular pressure $\left(\mathrm{IOP}_{\mathrm{G}}\right)$. Calculations of IOP-corrected $\mathrm{CH}$ and $\mathrm{CRF}$ were conducted according to Spörl et al $^{11}$ with references of IOP $=18 \mathrm{mmHg}$ and central corneal thickness $=540 \mu \mathrm{m}$, taking into account that the biomechanical properties of the eye are pressure dependent. ${ }^{19}$ The parameters used for analysis were then $\mathrm{CH}$ and $\mathrm{CRF}_{\text {corr }}$. Out of a minimum of four consecutive ORA measurements taken, mean values were calculated. None of the included patients presented with any known corneal abnormality.

\section{Statistics}

Statistical analysis was performed using SPSS (v 19.0; IBM Corporation, Armonk, NY, USA), SamplePower for SPSS (v 3.0; IBM Corporation), and Microsoft Excel for Windows 2007 (Microsoft Corporation, Redmond, WA, USA). Descriptive statistical analyses were performed to characterize the patients' clinical and functional data. Analysis included paired Student's $t$-test after KolmogorovSmirnov testing for normal distribution and calculation of correlation coefficients (Spearman's rho). Data were also fitted to multiple linear regression analyses; $t$-based $95 \%$ confidence intervals for the regression coefficients were used. For all tests, $P<0.05$ was considered to be statistically significant. For the number of eyes included into this study, power analysis evaluating changes of chamber angles and $\mathrm{CH}_{\text {corr }}$ resulted in a statistical power of $>85 \%$.

\section{Results}

Seventeen eyes of nine male patients with PG were included. A significant flattening of the AC angle in all eyes was imaged on AS-OCT (Figure 1 displays a representative example). The decrease in the chamber angle after PI was highly significant in all four quadrants $(P<0.001)$. The mean angles before PI were $57.0^{\circ} \pm 9.6^{\circ}, 56.1^{\circ} \pm 8.1^{\circ}, 55.8^{\circ} \pm 9.3^{\circ}$, and $55.8^{\circ} \pm 9.8^{\circ}$, and $44.1^{\circ} \pm 5.2^{\circ}, 46.8^{\circ} \pm 6.4^{\circ}, 44.2^{\circ} \pm 5.5^{\circ}$, $44.7^{\circ} \pm 5.8^{\circ}$ after PI for the temporal, nasal, superior, and inferior quadrants, respectively (Figure 2). The effect on chamber-angle reduction after PI was highest in the temporal quadrant, followed by the inferior, superior, and nasal quadrants $\left(\Delta=12.9^{\circ}, 10.9^{\circ}, 10.6^{\circ}\right.$, and $9.3^{\circ}$, respectively $)$. The mean volume of the AC decreased significantly from $213.1 \pm 36.4 \mathrm{~mm}^{3}$ before to $187.0 \pm 23.4 \mathrm{~mm}^{3}$ after PI $(P<0.001$; Figures 3 and 4$)$. 


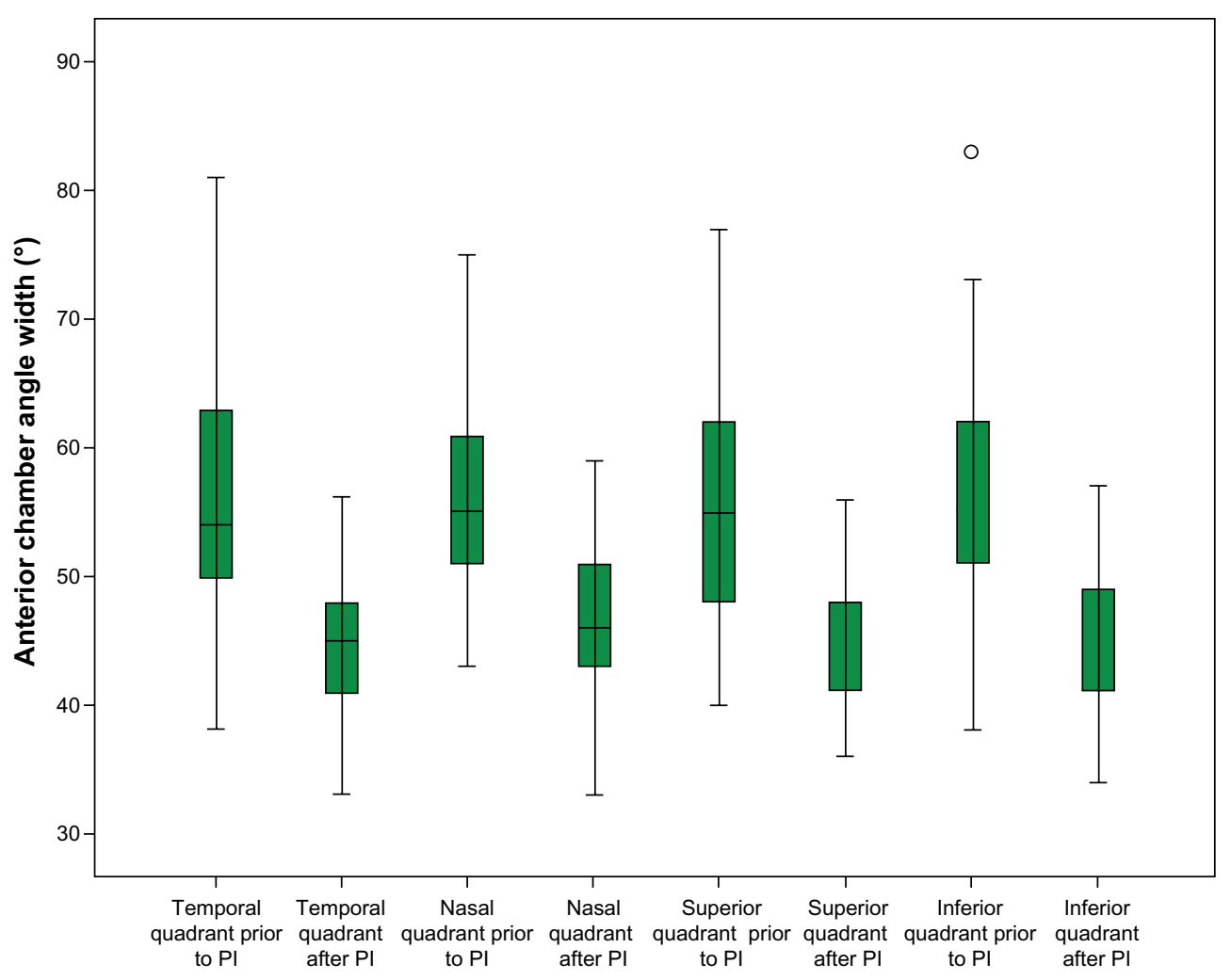

Figure 2 Box plot of anterior chamber angle values $\left(^{\circ}\right)$ before and after peripheral laser iridotomy (PI). Note: $P<0.001$ in all four quadrants (paired Student's $t$-test).

The corneal biomechanical properties did not change after PI (Table 2, Student's $t$-test $P=0.39$ and $P=0.44$ for $\mathrm{CH}_{\text {corr }}$ and $\mathrm{CRF}_{\text {corr }}$, respectively). $\mathrm{CH}_{\text {corr }}-\mathrm{CRF}_{\text {corr }}$ was $-0.76 \pm 1.77 \mathrm{mmHg}$ before and $-0.54 \pm 0.58 \mathrm{mmHg}$ after $\mathrm{PI}(P=0.97)$.

In correlation analysis, there was a strong and significant correlation of the superior and inferior angle width with pre-PI $\mathrm{CH}_{\text {corr }}$ (Spearman's rho=0.553 and $0.615, P<0.05$, respectively, Figure 5A and B). For the temporal and nasal angles, correlation with pre-PI $\mathrm{CH}_{\text {corr }}$ was not significant ( $r=0.460$ and $r=0.474, P=0.06$, respectively).
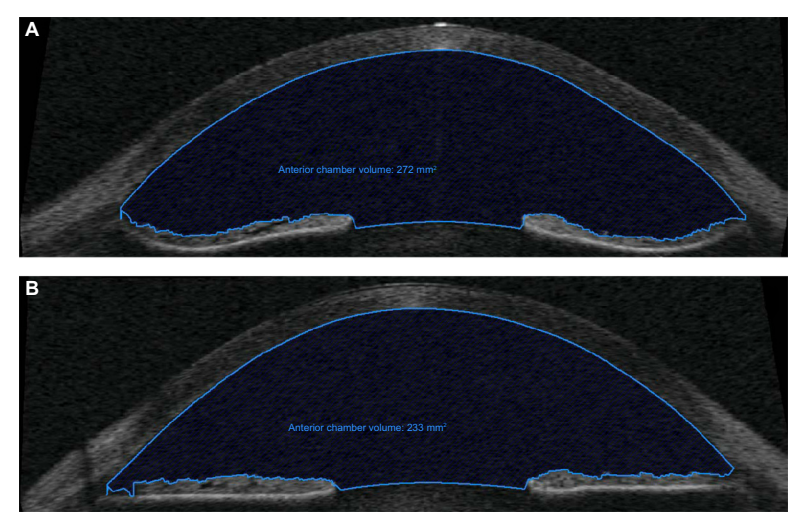

Figure 3 Changes of anterior chamber volume (transversal imaging) before (A) and after (B) peripheral laser iridotomy in the same eye.
Multiple regression analyses were performed to analyze the impact of corneal biomechanics on AS changes. In the modeling, neither $\mathrm{CH}$ nor CRF could predict angle changes or changes in the $\mathrm{AC}$ volume. However, when modeling for the preoperative inferior angle as the dependent variable, the parameters $\mathrm{CH}_{\text {corr }}, \mathrm{CRF}_{\text {corr }}$, age, and the spherical equivalent could explain $56.4 \%$ of the variance, with $\mathrm{CH}_{\text {corr }}$ being the only significant predictor $(P=0.04$; Table 3$)$.

The mean IOP decreased, yet not significantly, from $15.0 \pm 4.2 \mathrm{mmHg}$ to $13.2 \pm 2.3 \mathrm{mmHg}$ after PI $(P=0.13)$.

\section{Discussion}

In eyes with PDS/PG, PI equalizes the pressure between the anterior and posterior chamber, flattens the iris, and thus reverses posterior iris bowing. AC angle parameters imaged by AS-OCT are proven significantly greater in eyes with $\mathrm{PG}^{20}$ and an effect after PI is noted. ${ }^{21}$ Our results show a highly significant reduction of the AC width after PI visualized by AS-OCT in all meridians studied. Hereby, the largest effect was observed in the temporal quadrant and therefore not in the region where the PI was performed. The AC volume also decreased significantly after PI in PG eyes, which is in accordance with previously published results. ${ }^{22}$ AS-OCT is an emerging method for detailed imaging of AS structures in 


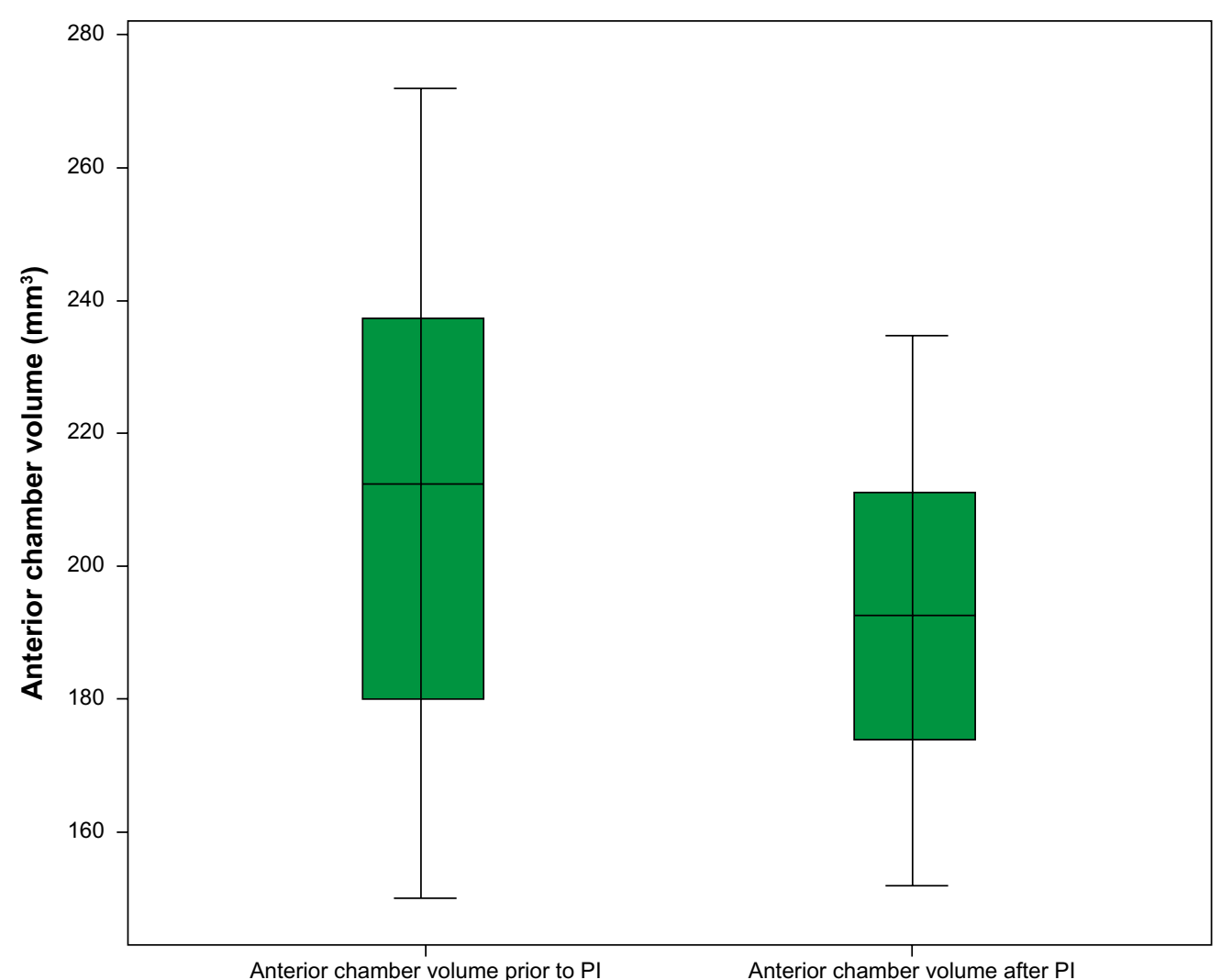

Figure 4 Box plot of anterior chamber volume values $\left(\mathrm{mm}^{3}\right)$ before and after peripheral laser iridotomy (PI).

Note: $P<0.00$ I (paired Student's $t$-test).

glaucoma. Previous studies including patients with primary angle closure have been able to illustrate significant widening of the $\mathrm{AC}$ angle after PI using $\mathrm{AS}-\mathrm{OCT}{ }^{8}$ It is a promising technology with a high reproducibility rate. ${ }^{23,24}$ Image resolution and results obtained are comparable to those obtained with UBM. ${ }^{8}$ The visualization of the scleral spur is even sharper $^{25}$ and precise evaluation of internal horizontal AC dimension can be considered superior to UBM analysis. ${ }^{20}$

A major finding of our study is that corrected $\mathrm{CH}$ is positively correlated with AC morphology in PG eyes, in particular

Table 2 Biomechanical properties

\begin{tabular}{lccl}
\hline Property $(\mathbf{m m H g})$ & $\begin{array}{c}\text { Baseline } \pm \\
\text { standard } \\
\text { deviation }\end{array}$ & After PI & Significance \\
\hline $\mathrm{IOP}_{\text {cc }}$ & $20.6 \pm 4.3$ & $20.2 \pm 4.4$ & 0.47 \\
$\mathrm{IOP}_{\mathrm{G}}$ & $19.3 \pm 4.8$ & $18.9 \pm 5.3$ & 0.35 \\
$\mathrm{CH}$ & $9.0 \pm 2.8$ & $9.1 \pm 2.6$ & 0.16 \\
$\mathrm{CH}_{\text {corr }}$ & $9.5 \pm 2.4$ & $9.5 \pm 2.2$ & 0.22 \\
$\mathrm{CRF}$ & $10.6 \pm 2.9$ & $10.3 \pm 3.2$ & 0.60 \\
$\mathrm{CRF}_{\text {corr }}$ & $10.2 \pm 2.7$ & $10.0 \pm 2.7$ & 0.25 \\
$\mathrm{CH}_{\text {corr }}-\mathrm{CRF}_{\text {corr }}$ & $-0.76 \pm \mathrm{I} .77$ & $-0.54 \pm 0.58$ & 0.49 \\
\hline
\end{tabular}

Abbreviations: $\mathrm{CH}$, corneal hysteresis; $\mathrm{CH}_{\text {corr, }}$ corrected corneal hysteresis; $\mathrm{CRF}$, corneal resistance factor; $\mathrm{CRF}_{\text {corr }}$ corrected corneal resistance factor; $1 \mathrm{OP}_{\mathrm{CC}}$ corneal compensated intraocular pressure; IOP $_{\mathrm{G}}$, Goldmann-equivalent intraocular pressure; PI, peripheral laser iridotomy. with the superior and inferior AC angles. PDS eyes are reported to have a flatter ${ }^{22}$ and larger cornea. ${ }^{3,26}$ The iris tissue in PDS eyes may be weaker or more flaccid and therefore more prone to stretching than in non-PDS eyes, ${ }^{27}$ and it can be assumed that with increasing hysteresis of the cornea these flaccid characteristics of the iris might be more pronounced.

In eyes with long-lasting $\mathrm{OAG}, \mathrm{CH}$ has been repeatedly reported to be lower than in healthy eyes, resulting in decreased damping properties and increased stiffness of the continuous collagenous sheaths of the eye, setting the focus of glaucoma pathogenesis in the region of the lamina cribrosa and optic-nerve head. ${ }^{10,12}$ The values of $\mathrm{CH}$ and $\mathrm{CRF}$ in our study population are within the range of healthy controls. ${ }^{11}$ One explanation for this finding might be the younger age of patients with PG (mean 42 years in our sample), as OAG patients are generally older and $\mathrm{CH}$ decreases with age. Further, the different $\mathrm{CH}$ values in OAG and PG could be due to the different glaucomatous pathogenesis. While lower $\mathrm{CH}$ in OAG indicates more advanced glaucoma and eyes with low $\mathrm{CH}$ are more sensitive to IOP elevations, ${ }^{28,29}$ in PG the opposite might be true: a higher $\mathrm{CH}$ compared with $\mathrm{OAG}$ patients is associated with larger AC angles and more severe bowing of the iris, and these eyes might have a higher risk of severe glaucomatous optic-nerve damage. 

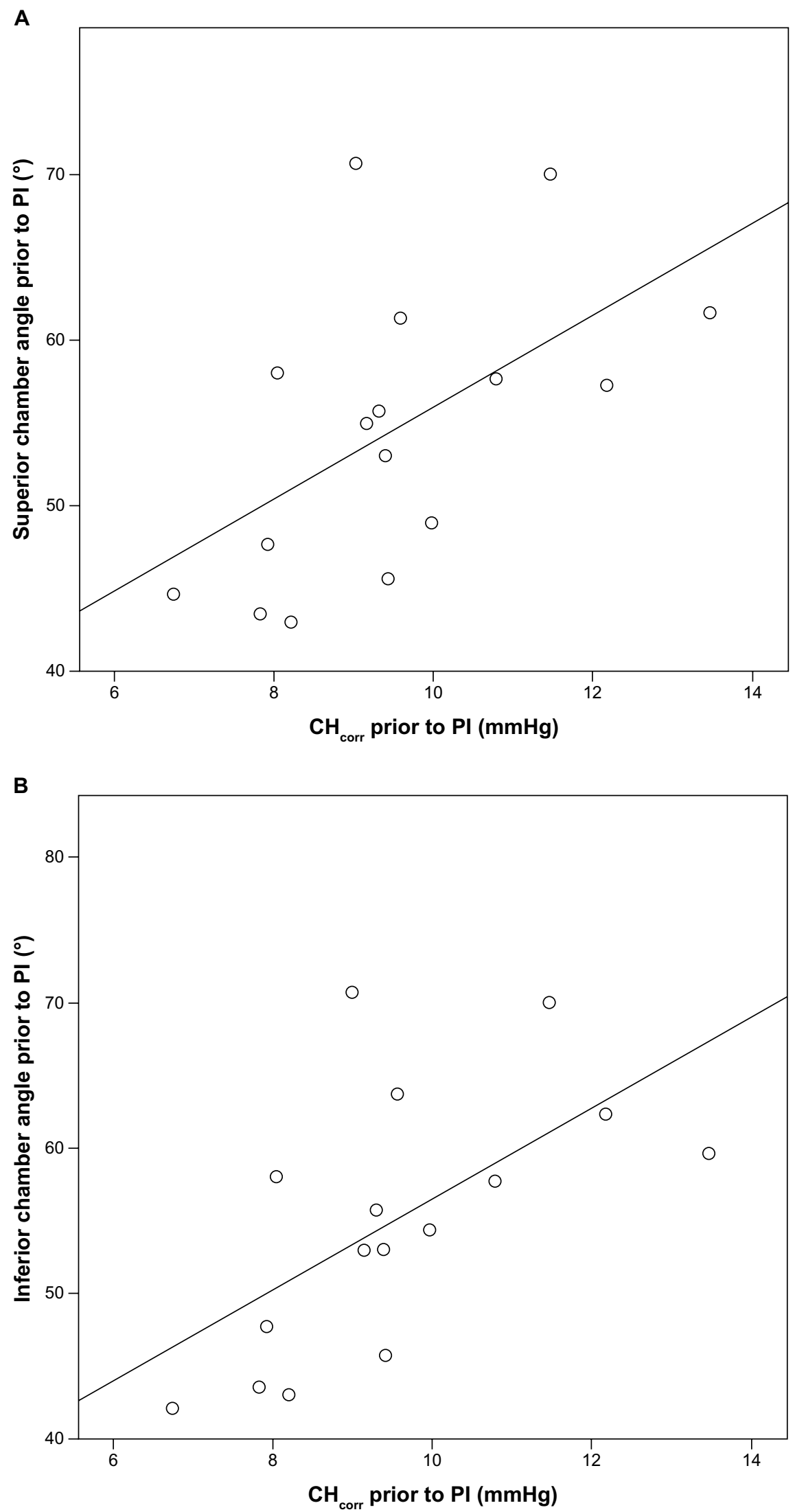

Figure 5 Significant correlation between corrected baseline corneal hysteresis $\left(\mathrm{CH}_{\text {corr }}\right)$ and superior $(\mathbf{A})$ and inferior $(\mathbf{B})$ angles. Note: Spearman's rho $P=0.553$ and $P=0.615$ for superior and inferior angles, respectively.

Abbreviations: $\mathrm{PI}$, peripheral laser iridotomy; $\mathrm{CH}_{\text {corr }}$, corrected corneal hysteresis. 
Table 3 Regression model with baseline inferior angle as the dependent variable

\begin{tabular}{|c|c|c|c|c|c|}
\hline \multirow[t]{2}{*}{ Model } & \multicolumn{2}{|c|}{ Unstandardized coefficient } & \multirow{2}{*}{$\begin{array}{l}\text { Standardized } \\
\text { coefficient } \\
\text { Beta }\end{array}$} & \multirow[t]{2}{*}{$t$} & \multirow[t]{2}{*}{ Significance } \\
\hline & B & SE & & & \\
\hline Constant & 7.40 & 17.70 & & 0.42 & 0.68 \\
\hline $\mathrm{CH}_{\text {corr }}(\mathrm{mmHg})$ & 7.14 & 3.10 & 1.37 & 2.30 & $0.04 *$ \\
\hline Spherical equivalent (D) & -3.55 & $\mathrm{I} .73$ & -0.55 & -2.06 & 0.06 \\
\hline Age (years) & 0.212 & 0.40 & 0.14 & 0.53 & 0.61 \\
\hline $\mathrm{CRF}_{\text {corr }}(\mathrm{mmHg})$ & -4.02 & 2.47 & -0.96 & -1.63 & 0.13 \\
\hline
\end{tabular}

$R^{2} 0.563$

Notes: $* p<0.05$.

Abbreviations: $\mathrm{CH}_{\text {corr }}$, corrected corneal hysteresis; $\mathrm{CRF}_{\text {corr }}$, corrected corneal resistance factor; $\mathrm{D}$, diopter; $\mathrm{IOP}_{\mathrm{cC}}$, corneal compensated intraocular pressure; $\mathrm{SE}$, standard error.

A difference between $\mathrm{CH}$ and $\mathrm{CRF}\left(\mathrm{CH}_{\text {corr }}-\mathrm{CRF}_{\text {corr }}\right)$ of zero or a slightly negative value stands for equilibration of viscous (CH) and total elastic (CRF) components. ${ }^{11}$ In this series, a negative value means reduced damping capacities and predominant elastic components.

The therapeutic effect of PI remains controversial: while preliminary success has been reported by Campbell and Schertzer ${ }^{30}$ and Gandolfi and Vecchi, ${ }^{31}$ who reported a decreased incidence of ocular hypertension, other groups such as Reistad et al ${ }^{32}$ or, most recently, Scott et al could not find a benefit of laser PI in preventing progression from PDS to $\mathrm{PG} .{ }^{33}$ Scott et al estimated iris concavity subjectively and did not measure changes of the anterior segment objectively. Thus, no morphological control of efficiency after PI could be performed. Accommodation, globe deformation caused by blinking, and physical exercise have been shown to increase iris concavity. ${ }^{1,34-36}$ These risk factors for an increase of IOP in PDS eyes decrease with age due to anatomical changes of the eye. ${ }^{1}$ Inclusion of older patients might therefore bias success of PI. Although the therapeutic effect of laser PI has not been yet validated in a prospective, representative clinical setting, it could be assumed that patients with PG, large $\mathrm{AC}$ angle, and higher $\mathrm{CH}$ could especially benefit from laser PI. In our study, patients with these characteristics showed a highly significant change in iris concavity.

Aptel et al observed a significant decrease in IOP after PI. ${ }^{22}$ The IOP in our sample decreased only marginally. Local and systemic therapy differed in some patients before and after the procedure, which might have effected the change.

This study has certain limitations. The small number of eyes included has resulted in high standard deviations compared with those of studies with larger patient collectives. We do acknowledge the possibility of statistical influence when including both eyes of a subject. Yet, statistical power remained $>85 \%$ when including only one eye per subject compared with all 17 eyes, indicating no relevant influence for the purposes of this study.

AS-OCT is helpful for the diagnosis of anterior-segment changes in PG as well as for the follow-up of patients with PG during medical treatment and after PI or surgical interventions. ${ }^{20}$ We observed highly significant changes of the anterior-segment via AS-OCT. PI did not influence the biomechanical properties of PDS and PG eyes significantly. Yet, biomechanical properties in these eyes seem to be higher than in other glaucoma subgroups. Due to embryogenesis, anatomical characteristics in corneal tissue measured in vivo via ORA might lead to conclusions of biomechanical features of the iris.

Further studies including a larger number of treated eyes and possibly differentiating between PDS and PG are warranted. Longitudinal data concerning the influence of $\mathrm{CH}$ on the progression of PG would be of great interest.

\section{Conclusion}

PI in eyes with PG results in a highly significant reduction in the AC angles and volume as visualized by AS-OCT, with the largest effect seen in the temporal quadrant. $\mathrm{CH}$ is strongly positively correlated with the superior and inferior preoperative $\mathrm{AC}$ angles, emphasizing the importance of the biomechanical properties of the cornea for glaucoma pathogenesis in $\mathrm{PG}$, but corneal biomechanical properties cannot predict PI-related AC changes.

\section{Disclosure}

The authors declare no conflicts of interest in this work.

\section{References}

1. Niyadurupola N, Broadway DC. Pigment dispersion syndrome and pigmentary glaucoma - a major review. Clin Experiment Ophthalmol. 2008;36(9):868-882.

2. Schwenn O, Shah B, Vogel A, Yun SH. [Nd-YAG laser iridotomy in pigment dispersion syndrome and pigment dispersion glaucoma]. Ophthalmologe. 2003;100(5):406-410. German. 
3. Kandani FN, Dorairaj S, Langlieb AM, et al. Ultrasound biomicroscopy in asymmetric pigment dispersion syndrome and pigmentary glaucoma. Arch Ophthalmol. 2006;124(11):1573-1576.

4. Campbell DG. Pigmentary dispersion and glaucoma. A new theory. Arch Ophthalmol. 1979;97:1667-1672.

5. Kampik A, Green WR, Quigley HA, Pierce LH. Scanning and transmission electron microscopic studies of two cases of pigment dispersion syndrome. Am J Ophthalmol. 1981;91(5):573-587.

6. Radhakrishnan S, Rollins AM, Roth JE, et al. Real-time optical coherence tomography of the anterior segment at $1310 \mathrm{~nm}$. Arch Ophthalmol. 2001;119(8):1179-1185.

7. Karickhoff JR. Pigmentary dispersion syndrome and pigmentary glaucoma: a new mechanism concept, a new treatment, and a new technique. Ophthalmic Surg. 1992;23(4):269-277.

8. See JL, Chew PT, Smith SD, et al. Changes in anterior segment morphology in response to illumination and after laser iridotomy in Asian eyes: an anterior segment OCT study. Br J Ophthalmol. 2007;91(11): 1485-1489.

9. Luce DA. Determining in vivo biomechanical properties of the cornea with an ocular response analyzer. $J$ Cataract Refract Surg. 2005;31(1):156-162.

10. Cankaya AB, Anayol A, Özcelik D, Demirdogen E, Yilmazbas P. Ocular response analyzer to assess corneal biomechanical properties in exfoliation syndrome and exfoliative glaucoma. Graefes Arch Clin Exp Ophthalmol. 2012;250(2):255-260.

11. Spörl E, Terai N, Haustein M, Böhm AG, Raiskup-Wolf F, Pillunat LE. [Biomechanical condition of the cornea as a new indicator for pathological and structural changes.] Ophthalmologe. 2009;106(6):512-520. German.

12. Herndon WL, Weizer JS, Stinnett SS. Central corneal thickness as a risk factor for advanced glaucoma damage. Arch Ophthalmol. 2004;122(1):17-21.

13. Sullivan-Mee M, Billingsley SC, Patel AD, Halverson KD, Alldredge BR, Qualls C. Ocular Response Analyzer in subjects with and without glaucoma. Optom Vis Sci. 2008;85(6):463-470.

14. Kirwan C, O'Malley D, O'Keefe M. Corneal hysteresis and corneal resistance factor in keratoectasia: findings using the Reichert ocular response analyzer. Ophthalmologica. 2008;222(5):334-347.

15. Carbonaro F, Andrew T, Mackey DA, Spector TD, Hammond CJ. The heritability of corneal hysteresis and ocular pulse amplitude: a twin study. Ophthalmology. 2008;115(9):1545-1549.

16. Shah S, Laiquzzaman M, Bhojwani R, Mantry S, Cunliffe I. Assessment of the biomechanical properties of the cornea with the ocular response analyzer in normal and keratoconic eyes. Invest Ophthalmol Vis Sci. 2007;48(7):3026-3031.

17. Ortiz D, Piñero D, Shabayek MH, Arnalich-Montiel F, Alió JL. Corneal biomechanical properties in normal, post-laser in situ keratomileusis, and keratoconic eyes. J Cataract Refract Surg. 2007;33(8):1371-1375.

18. Kirwan C, O'Keefe M, Lanigan B. Corneal hysteresis and intraocular pressure measurement in children using the reichert ocular response analyzer. Am J Ophthalmol. 2006;142(6):990-992.

19. Hirneiss C, Neubauer AS, Yu A, Kampik A, Kernt M. Corneal biomechanics measured with the ocular response analyser in patients with unilateral open-angle glaucoma. Acta Ophthalmol. 2011;89(2): e189-e192.
20. Dinc UA, Kulacoglu DN, Oncei B, Yalvac IS. Quantitative assessment of anterior chamber parameters in pigmentary glaucoma using slitlamp optical coherence tomography. Eur J Ophthalmol. 2010;20(4): 702-707.

21. Laemmer R, Mardin CY, Juenemann AG. Visualization of changes of the iris configuration after peripheral laser iridotomy in primary melanin dispersion syndrome using optical coherence tomography. J Glaucoma. 2008;17(7):569-577.

22. Aptel F, Beccat S, Fortoul V, Denis P. Biometric analysis of pigment dispersion syndrome using anterior segment optical coherence tomography. Ophthalmology. 2011;118(8):1563-1570.

23. Müller M, Dahmen G, Pörksen E, et al. Anterior chamber angle measurement with optical coherence tomography: intraobserver and interobserver variability. J Cataract Refract Surg. 2006;32(11):1803-1808.

24. Radhakrishnan S, See J, Smith SD, et al. Reproducibility of anterior chamber angle measurements obtained with anterior segment optical coherence tomography. Invest Ophthalmol Vis Sci. 2007;48(8):3683-3688.

25. Dada T, Sihota R, Gadia R, Aggarwal A, Mandal S, Gupta V. Comparison of anterior segment optical coherence tomography and ultrasound biomicroscopy for assessment of the anterior segment. $J$ Cataract Refract Surg. 2007;33(5):837-840.

26. Sokolic P. Megalocornea: report of a case with the signs of pigmentary glaucoma. Am J Ophthalmol. 1964;58:486-490.

27. Trastman-Caruso E, Dorairaj S, Barocas VH, Tello C, Liebmann JM, Ritch R. Pigment dispersion syndrome patients do not have larger-than-normal irides. J Glaucoma. 2010;19(7):493-496.

28. Congdon NG, Broman AT, Bandeen-Roche K, Grover D, Quigley HA. Central corneal thickness and corneal hysteresis associated with glaucoma damage. Am J Ophthalmol. 2006;141(5):868-875.

29. Wells AP, Garway-Heath DF, Poostchi A, Wong T, Chan KC, Sachdev N. Corneal hysteresis but not corneal thickness correlates with optic nerve surface compliance in glaucoma patients. Invest Ophthalmol Vis Sci. 2008;49(8):3262-3268

30. Campbell DG, Schertzer RM. Pathophysiology of pigment dispersion syndrome and pigmentary glaucoma. Curr Opin Ophthalmol. 1995;6(2):96-101.

31. Gandolfi SA, Vecchi M. Effect of a YAG laser iridotomy on intraocular pressure in pigment dispersion syndrome. Ophthalmology. 1996;103(10):1693-1695

32. Reistad CE, Shields MB, Campbell DG, Ritch R, Wang JC, Wand M; American Glaucoma Society Pigmentary Glaucoma Iridotomy Study Group. The influence of peripheral iridotomy on the intraocular pressure course in patients with pigmentary glaucoma. $J$ Glaucoma. 2005;14(4):255-259.

33. Scott A, Kotecha A, Bunce C, et al. YAG laser peripheral iridotomy for the prevention of pigment dispersion glaucoma a prospective, randomized, controlled trial. Ophthalmology. 2011;118(3):468-473.

34. Balidis MO, Bunce C, Sandy CJ, Wormald RP, Miller MH. Iris configuration in accommodation in pigment dispersion syndrome. Eye. 2002;16(6):694-700

35. Liebmann JM, Tello C, Chew SJ, Cohen H, Ritch R. Prevention of blinking alters iris configuration in pigment dispersion syndrome and in normal eyes. Ophthalmology. 1995;102(3):446-455.

36. Jensen PK, Nissen O, Kessing SV. Exercise and reversed pupillary block in pigmentary glaucoma. Am J Ophthalmol. 1995;120(1):110-112.
Clinical Ophthalmology

\section{Publish your work in this journal}

Clinical Ophthalmology is an international, peer-reviewed journal covering all subspecialties within ophthalmology. Key topics include: Optometry; Visual science; Pharmacology and drug therapy in eye diseases; Basic Sciences; Primary and Secondary eye care; Patient Safety and Quality of Care Improvements. This journal is indexed on Submit your manuscript here: http://www.dovepress.com/clinical-ophthalmology-journal
Dovepress

PubMed Central and CAS, and is the official journal of The Society of Clinical Ophthalmology (SCO). The manuscript management system is completely online and includes a very quick and fair peer-review system, which is all easy to use. Visit http://www.dovepress.com/ testimonials.php to read real quotes from published authors. 